\title{
Risk of cardiovascular events in people prescribed glucocorticoids with iatrogenic Cushing's syndrome: cohort study
}

\author{
(C) $(1) \Theta$ OPEN ACCESS
}

\section{Laurence Fardet associate professor and senior consultant in internal medicine ${ }^{1234}$, Irene Petersen principal research associate in statistics and epidemiology ${ }^{4}$, Irwin Nazareth professor in primary care and population sciences and senior academic general practitioner ${ }^{14}$}

${ }^{1}$ MRC General Practice Research Framework, University College London Medical School, London, UK; ${ }^{2}$ AP-HP Hospital Saint-Antoine, Service de Médecine Interne, Paris, France; ${ }^{3}$ Université Pierre et Marie Curie, UPMC Paris 6, Faculté de Médecine, Paris, France; ${ }^{4}$ Research Department of Primary Care and Population Health, University College London Medical School, London, UK

\begin{abstract}
Objective To investigate whether there is an increased risk of cardiovascular events in people who exhibit iatrogenic Cushing's syndrome during treatment with glucocorticoids.

Design Cohort study.

Setting 424 UK general practices contributing to The Health Improvement Network database.
\end{abstract}

Participants People prescribed systemic glucocorticoids and with a diagnosis of iatrogenic Cushing's syndrome $(n=547)$ and two comparison groups: those prescribed glucocorticoids and with no diagnosis of iatrogenic Cushing's syndrome $(n=3231)$ and those not prescribed systemic glucocorticoids $(n=3282)$.

Main outcome measures Incidence of cardiovascular events within a year after diagnosis of iatrogenic Cushing's syndrome or after a randomly selected date, and association between iatrogenic Cushing's syndrome and risk of cardiovascular events.

Results 417 cardiovascular events occurred in 341 patients. Taking into account only the first event by patient (coronary heart disease $n=177$, heart failure $n=101$, ischaemic stroke $n=63$ ), the incidence rates of cardiovascular events per 100 person years at risk were 15.1 (95\% confidence interval 11.8 to 18.4) in those prescribed glucocorticoids and with a diagnosis of iatrogenic Cushing's syndrome, 6.4 (5.5 to 7.3 ) in those prescribed glucocorticoids without a diagnosis of iatrogenic Cushing's syndrome, and 4.1 (3.4 to 4.8) in those not prescribed glucocorticoids. In multivariate analyses adjusted for sex, age, intensity of glucocorticoid use, underlying disease, smoking status, and use of aspirin, diabetes drugs, antihypertensive drugs, lipid lowering drugs, or oral anticoagulant drugs, the relation between iatrogenic Cushing's syndrome and cardiovascular events was strong (adjusted hazard ratios 2.27 (95\% confidence interval 1.48 to 3.47 ) for coronary heart disease, 3.77 ( 2.41 to 5.90 ) for heart failure, and 2.23 (0.96 to 5.17 ) for ischaemic cerebrovascular events). The adjusted hazard ratio for any cardiovascular event was 4.16 ( 2.98 to 5.82 ) when the group prescribed glucocorticoids and with iatrogenic Cushing's syndrome was compared with the group not prescribed glucocorticoids.

Conclusion People who use glucocorticoids and exhibit iatrogenic Cushing's syndrome should be aggressively targeted for early screening and management of cardiovascular risk factors.

\section{Introduction}

About $1 \%$ of the general population are long term users of systemic glucocorticoids ${ }^{12}$ and about two thirds exhibit iatrogenic manifestations related to excessive exposure to glucocorticoids, ${ }^{3}$ many after only a few weeks or months of use. Although iatrogenic Cushing's syndrome may vary in intensity and clinical presentation (the characteristic muscular or cutaneous disorders may be present or absent for example), the condition is mostly characterised by a typical "cushingoid adiposity," reflecting less weight gain than abnormalities of adipose tissue distribution, with hypertrophy of adipose tissue in the face ("moon face"), dorsocervical region ("buffalo hump", double chin, accumulation of fat in the supraclavicular area), and abdomen ("pendulum" abdomen) and thinning of the subcutaneous adipose tissue of the limbs. ${ }^{4}$ This typical redistribution of the adipose tissue induced by glucocorticoids can be considered as an iatrogenic form of lipodystrophy. ${ }^{5}$ It is known that the glucocorticoid induced morphological changes are associated with cardiovascular risk factors such as high blood pressure, blood glucose and triglyceride levels, and low high density lipoprotein cholesterol levels, ${ }^{6}$ and that many forms of lipodystrophy are associated with metabolic disorders and premature atherosclerosis. ${ }^{7-10} \mathrm{We}$ therefore hypothesised that the increased risk of cardiovascular events observed in 
people treated with glucocorticoids ${ }^{11-13}$ is strongly associated with those who develop iatrogenic Cushing's syndrome compared with those who do not.

\section{Methods}

About $98 \%$ of the population in the United Kingdom is registered with a general practitioner. ${ }^{14}$ The Health Improvement Network (THIN) is a database of electronic medical records from UK general practices. Participating general practitioners systematically and prospectively retrieve and enter clinical information on patients, including personal data, diagnoses, and prescriptions so that the database provides a longitudinal medical record for each patient. All sections of the population are represented in THIN. The data are collected in a non-interventional way during routine general practice and therefore reflect "real life" clinical care. The information is continually updated. Information from secondary care and other medically related information received by the practice is transcribed and entered retrospectively. Prescribing by general practitioners is particularly well recorded since the computerised entry made by the doctor is also used as the prescription form. Previous comparison with external statistics and other independent studies have shown that both the clinical diagnostic and prescribing information are well recorded and accurate. ${ }^{15-18}$ THIN, however, represents data collected from the general practitioner's medical records and reflects only those events that are deemed to be relevant to the patient's care and not for research purposes. In most cases a medicine prescribed for the first time is temporally linked with a medical event record (symptom or diagnosis), but no permanent link exists between a prescribed treatment and the reason for prescription. Drugs prescribed by hospital doctors or other specialists do not appear in THIN data unless the treatment is to be continued by the general practitioner. However, due to the constraints of specialist and hospital prescribing budgets many prescriptions issued outside of the general practice are sufficient to cover only the first seven days. After this time the patient usually obtains subsequent prescriptions from their general practitioner. Lastly, some of the drugs used in the United Kingdom are obtained over-the-counter so are not entered in general practitioner records. For this study we used data from 1 January 1990 to 31 December 2008 from 424 general practices and we excluded events that occurred within six months after registration to include only incident cases of outcomes. ${ }^{19}$

\section{Prescriptions of glucocorticoids}

Each prescription of a drug is recorded in THIN as encrypted multilex codes, along with reference to the chapter in the British National Formulary describing the drug. ${ }^{20}$ We selected all glucocorticoids prescribed orally or by intramuscular or intravenous injection and this included prednisolone, prednisone, dexamethasone, triamcinolone, betamethasone,

methylprednisolone, and deflazacort. We included people aged 18 years and older and identified all who were prescribed such treatment. For multiple consecutive prescriptions we considered that these were part of a unique course of treatment if the gap between two consecutive prescriptions was less than three months. For each course we defined the treatment duration as the time from the first to the last prescription plus the duration of the last prescription. Data on adherence to treatment are not routinely recorded in THIN. To ensure that our samples comprised those people who were most likely taking the drug, we restricted our populations of glucocorticoid users to those who received at least two successive prescriptions for glucocorticoids. We calculated the average daily dosage by multiplying the number of pills prescribed by the dose per pill (calculated in prednisone equivalent) and then divided this by the number of days for which the drug was prescribed. The medical diagnosis recorded on the date of starting glucocorticoids was used as the indication for the prescription. We excluded people taking substitutive glucocorticoids for adrenal insufficiency.

\section{Identification of iatrogenic Cushing's syndrome}

All diagnoses and symptoms are recorded in THIN using the Read classification system. ${ }^{21}$ Using the method described previously ${ }^{22}$ we retained four codes to define iatrogenic Cushing's syndrome: iatrogenic Cushing's syndrome, drug induced Cushing's syndrome, steroid facies, and cushingoid facies.

\section{Study groups}

We selected two cohorts from patients recorded in THIN. The first comprised all those prescribed systemic glucocorticoids and the other those who were never prescribed systemic glucocorticoids. Among patients prescribed glucocorticoids, we defined those with a recorded diagnosis of iatrogenic Cushing's syndrome as the exposed group and those without a recorded diagnosis of iatrogenic Cushing's syndrome as eligible for inclusion in the first comparison group. Anyone in the second cohort was eligible to be included in the second comparison group, comprising those who had never been prescribed systemic glucocorticoids. When selecting the comparison groups we stratified the samples to ensure the same distribution among groups for sex and age (within 10 year age bands). Additionally, for the first comparison group we stratified the sample to ensure that the distribution for duration of use of glucocorticoids and initial dosage were similar to that of the group prescribed glucocorticoids and with iatrogenic Cushing's syndrome. Lastly, because of the possible association between indications for treatment with glucocorticoids and cardiovascular disease, in the comparison groups we preferentially selected people with the same underlying diseases as those in the group prescribed glucocorticoids and with iatrogenic Cushing's syndrome. We selected up to six times as many people in each of the two comparison groups as those in the group prescribed glucocorticoids with iatrogenic Cushing's syndrome. Patients in both groups were selected at random from the pool of eligible patients. The start of the follow-up period for the analyses was defined by an index date. For those from the group prescribed glucocorticoids with iatrogenic Cushing's syndrome, this index date was defined as the first record of iatrogenic Cushing's syndrome. For patients in the comparison groups the index date was randomly selected from within the time they were registered with the general practice. In the case of those prescribed glucocorticoids with no record of iatrogenic Cushing's syndrome, this period was restricted to that during which they were prescribed the drug.

\section{Covariates of interest}

We identified smoking status based on the nearest record before the index date, including data up to five years before this date. For each included patient we extracted clinical data (height, weight, and blood pressure) and biological data (fasting glucose, total cholesterol, and triglycerides levels) from his or her medical records. Data were collected for two periods: in the six months before the index date and in the six months after the index date. 
Moreover, we searched the drug treatment files for relevant prescriptions. If patients had at least two prescriptions for either diabetes drugs, antihypertensive drugs, cholesterol lowering drugs, oral anticoagulants, or antiplatelet drugs we defined them as being treated with that particular drug. To ascribe the hazard of cardiovascular events to the presence of iatrogenic Cushing's syndrome, we examined the risk of some diseases which were a priori not related to Cushing's syndrome. For cardiovascular disorders we searched for valvular heart diseases. For non-cardiovascular events, we defined impacted cerumen in the ear (one of the most common diagnoses recorded in THIN), sprain, and neoplasm (malignant neoplasm of digestive organs, skin, breast, or genitourinary organ) as negative control diseases.

\section{Identification of cardiovascular events}

Using the same method as for iatrogenic Cushing's syndrome, we developed Read code lists to identify recorded diagnoses of either coronary heart disease, heart failure, or ischaemic cerebrovascular events. To exclude a possible but not confirmed diagnosis we only selected stringent codes-for example, acute myocardial infarction, cardiac failure, transient cerebral ischaemia, stroke. Moreover, we also examined anonymised free text associated with records of death to capture fatal events that may not have been recorded by Read codes.

\section{Statistical analysis}

In each group we calculated the incidence of cardiovascular events within the first year after the index date by dividing the number of newly diagnosed cases by the follow-up time up to one year after the index date. If patients had several events we censored them at their first event. We compared the three groups to assess hazard ratios associated with iatrogenic Cushing's syndrome. We adjusted the estimated hazard ratio for age (continuous variable); sex; underlying disease; smoking status; history of prescription for aspirin, oral anticoagulants, diabetes drugs, antihypertensive drugs, or cholesterol lowering drugs; and initial dosage (continuous variable) and duration (continuous variable) of glucocorticoid use for people prescribed the drug. Using Cox proportional hazards models we accounted for clustering at the general practice level. Proportional hazard assumptions were checked graphically and by analysing Schoenfeld residuals. We checked linearity for continuous variables by comparing two models, one with the linear term and the other with the categories, using the log likelihood ratio test. Continuous variables are presented as medians and 25th to 75 th centile values. Categorical variables are presented as proportions, with $95 \%$ confidence intervals indicating precision of estimates. Incidence rates are reported per 100 person years at risk. All analyses were done using Stata, version 11.1.

\section{Results}

A diagnosis of iatrogenic Cushing's syndrome was found in the medical records of 585 people. Among these patients, 38 (6.5\%) were prescribed glucocorticoids at some point in their medical history but as they were not receiving them at the time iatrogenic Cushing's syndrome was recorded they were not included in the analyses. The 547 remaining patients prescribed glucocorticoids and with iatrogenic Cushing's syndrome were mainly women $(n=391,71.5 \%)$, with a median age of 64.7 (interquartile range 51.1-74.4) years (table $1 \Downarrow$ ). The group prescribed glucocorticoids but without iatrogenic Cushing's syndrome and the group not prescribed glucocorticoids were made up of 3231 patients (women: 2301 (71.2\%), median age 64.3 (interquartile range 51.0-74.4) years) and 3282 patients (women: 2346 (71.5\%), median age 63.7 (50.9-74.4) years), respectively (table 1 ). Table $2 \Downarrow$ lists their baseline clinical and biological characteristics and changes in the variables over time. Six months after the index date, people with a diagnosis of iatrogenic Cushing's syndrome had higher body mass index, higher blood pressure, and higher fasting glucose, total cholesterol, and triglyceride levels than people from the two comparison groups. Moreover, within the year after the index date they were more likely to be prescribed antihypertensive and diabetes drugs (table $3 \Downarrow$ ).

\section{Incidence of cardiovascular events}

Overall, 417 cardiovascular events were recorded within the year after the index date in 341 patients. Taking into account only the first cardiovascular event by patient, coronary heart disease was the most common $(n=177,52 \%)$ followed by heart failure $(n=101,30 \%)$ and cerebrovascular events $(n=63,18 \%$, table $4 \Downarrow$ ). The incidence of cardiovascular events was higher in the group prescribed glucocorticoids with iatrogenic Cushing's syndrome (incidence rate per 100 person years at risk $15.1,95 \%$ confidence interval 11.8 to 18.4 ) than in the group prescribed glucocorticoids but without iatrogenic Cushing's syndrome (6.4, 5.5 to 7.3$)$ or in the group not prescribed glucocorticoids (4.1, 3.4 to 4.8 , figure $\Downarrow$ ).

\section{Association between iatrogenic Cushing's syndrome and cardiovascular events}

Compared with the group prescribed glucocorticoids without iatrogenic Cushing's syndrome, the adjusted overall hazard ratio of developing a cardiovascular event for those prescribed glucocorticoids with iatrogenic Cushing's syndrome was 2.74 ( $95 \%$ confidence interval 2.06 to 3.62 , table $5 \Downarrow$ ). Analyses by the type of outcome indicated that patients prescribed glucocorticoids with iatrogenic Cushing's syndrome were at higher risk of coronary heart disease and cardiac insufficiency than those prescribed glucocorticoids without iatrogenic Cushing's syndrome (table 5). Patients prescribed glucocorticoids with iatrogenic Cushing's syndrome had a higher adjusted hazard ratio of any cardiovascular events (4.16, 2.98 to 5.82) compared with those not prescribed glucocorticoids (table 5). The results were similar when people with a history of cardiovascular events $(n=1004)$ were excluded from the analyses: adjusted hazard ratios of all cardiovascular events 2.56 (1.66 to 3.94) compared with patients prescribed glucocorticoids without iatrogenic Cushing's syndrome and 4.26 ( 2.49 to 7.29 ) compared with the group not prescribed glucocorticoids.

\section{Risk of negative control diseases}

Compared with patients prescribed glucocorticoids and without iatrogenic Cushing's syndrome, those with a diagnosis of iatrogenic Cushing's syndrome were not at higher risk for any of the diseases chosen as negative controls (table $6 \Downarrow$ ). Compared with people not prescribed glucocorticoids, those prescribed glucocorticoids with iatrogenic Cushing's syndrome were at higher risk of a diagnosis of malignant neoplasm.

\section{Discussion}

Patients prescribed systemic glucocorticoids who developed iatrogenic Cushing's syndrome had nearly a three times greater risk of cardiovascular disease, including coronary heart disease, heart failure, and cerebrovascular disease than patients prescribed glucocorticoids who were not known to have developed a cushingoid appearance. This risk increased to over 
fourfold in comparison with people not prescribed glucocorticoids. These results raise the question of whether glucocorticoids increase the risk of cardiovascular events in all patients or only in those who develop iatrogenic Cushing's syndrome.

\section{Comparison with other studies}

Glucocorticoid treatment is associated with an increased risk of cardiovascular events $\mathrm{s}^{11-13}$ and there is a reasonable clinical and biological basis on which to hypothesise that this risk is higher in people who develop a cushingoid appearance. Firstly, even though no consensual definition exists, the diagnosis of iatrogenic Cushing's syndrome is mostly based on a typical distribution of the adipose tissue. Indeed, many people prescribed glucocorticoids do not just gain weight, they also present with localised hypertrophy of adipose tissue including the typical "moon face," double chin, "buffalo hump," "bull neck," or "pendulum" abdomen. This central hypertrophy of adipose tissue is probably associated with a concomitant thinning of the subcutaneous adipose tissue of the limbs. ${ }^{4}$ This typical cushingoid adiposity is associated with metabolic disorders such as high blood pressure, high fasting blood glucose and triglycerides levels, and low high density lipoprotein cholesterol levels. ${ }^{6}$ Secondly, the glucocorticoid induced redistribution of adipose tissue can be considered as a form of iatrogenic lipodystrophy. ${ }^{5}$ Many forms of lipodystrophy have been associated with a high risk of type 2 diabetes, hypertension, dyslipidaemia, and premature atherosclerosis ${ }^{7-10} 2324$ and it has been shown that people with the Dunnigan-type lipodystrophy have almost a six times increased risk of coronary heart disease compared with controls. ${ }^{8}$ Lastly, glucocorticoid induced Cushing's syndrome and the metabolic syndrome share clinical (for example, central adiposity) and biological (for example, dysglycaemia, dyslipidaemia, hypertension) features, and multiple lines of evidence link disordered glucocorticoid metabolism to the metabolic syndrome. ${ }^{25}$ Central obesity has been suggested to reflect "Cushing's disease of the omentum," and the metabolic syndrome a mild form of Cushing's syndrome. $^{25} 26$

In daily practice some patients who are adherent to glucocorticoids will never exhibit a cushingoid appearance, whereas some others develop severe cushingoid adiposity after only a few days or weeks of treatment. In a previous prospective study of patients prescribed glucocorticoids for vasculitis or connective tissue diseases, we found that some patients' characteristics (for example, female sex, younger age, baseline higher body mass index) were strongly associated with an increased risk of abnormalities of adipose tissue distribution. ${ }^{627}$ In another prospective study, the baseline level of some adipokines (for example, leptin, resistin) was found to be predictive of the occurrence of central adipose tissue hypertrophy in people taking glucocorticoids. ${ }^{28}$ In these studies the biological inflammatory markers improved both in patients who developed a cushingoid appearance during follow-up and in those who did not, indirectly reflecting a relatively similar level of adherence to glucocorticoids. If some patients without cushingoid adiposity are probably poorly adherent to glucocorticoids, it is noteworthy that the presence of morphological changes is not synonymous with optimal adherence to the drug as some patients with a cushingoid appearance report being poorly adherent to glucocorticoids. ${ }^{29}$

Multiple pathways may be involved in the increased risk of cardiovascular events in people who develop iatrogenic Cushing's syndrome. ${ }^{30}$ Some well known cardiovascular risk factors, such as hypertension, hyperglycaemia, and dyslipidaemia, are more commonly observed in those people, probably because of an increase of visceral obesity. ${ }^{31}$ However, the development of cardiovascular disease may also be related to some mechanisms other than the metabolic syndrome or insulin resistance. For instance, we found that patients with iatrogenic Cushing's syndrome were at high risk of heart failure. Heart failure could represent a chronic complication of increased cardiometabolic risk but its evolution would be expected to be more chronic than the time course of the current observations. It is thus possible that other mechanisms besides atherosclerosis are involved. Cardiac abnormalities, including cardiomegaly, dilated cardiomyopathy, and congestive heart failure are frequent findings in people with congenital and acquired generalised lipodystrophy, but the mechanisms involved in the development of these conditions are unclear. ${ }^{32}$ Previous research in patients with impaired glucose tolerance or type 2 diabetes has suggested that accumulation of triglycerides in the myocardium can cause cardiac steatosis, which is associated with impaired left ventricular filling dynamics. ${ }^{33-35}$ Patients with lipodystrophy have ectopic accumulation of fat in organs such as liver and muscle, but whether fat is deposited in the myocardium of these patients remains to be assessed. Moreover, a hypercoagulability state has been reported in patients with endogenous Cushing's syndrome. $^{36}$

\section{Strengths and weaknesses of the study}

Our study has several strengths. We used a large population based sample of patients of both sexes and across all age groups. Moreover, the underlying disease had to be taken into account in the analyses since many diseases for which systemic glucocorticoids are indicated (asthma, chronic obstructive pulmonary disease, rheumatoid arthritis, giant cell arteritis) may be associated by themselves with an increased risk of cardiovascular disease..$^{37-40}$ The number of patients included in the study enabled analyses to be adjusted for underlying disease and other potential confounders such as drug prescriptions. In our study the two groups of patients treated with glucocorticoids differed essentially by an entry of iatrogenic Cushing's syndrome in their medical records. Both groups were treated for a similar duration and with a similar dosage of glucocorticoids, and they had comparable underlying diseases. Hence the heightened risk of cardiovascular events observed in patients with iatrogenic Cushing's syndrome was not due to indication bias as might have been determined by the disease. Moreover, we accounted for clustering at the general practice level since we thought that doctors who are more likely to record iatrogenic Cushing's syndrome may also be ones more likely to record other outcomes such as cardiovascular events. Lastly, we found than the risk of negative control diseases was not higher in people with iatrogenic Cushing's syndrome than in people without iatrogenic Cushing's syndrome, which reinforces the relation between morphological changes and cardiovascular events.

Our study does, however, have some limitations. Firstly, even though it was likely that the iatrogenic Cushing's syndrome recorded by doctors mostly reflected abnormalities of adipose tissue distribution, our study did not assess fat distribution using reference methods such as dual x ray absorptiometry,

tomodensitometry, or magnetic resonance imaging. Secondly, iatrogenic Cushing's syndrome is not always recorded by doctors, and some milder forms were more than likely not recorded. For this reason, some patients prescribed glucocorticoids with no recorded diagnosis of iatrogenic Cushing's syndrome may have been subject to misclassification. This potential classification bias could have led to an 
underestimation of the effect of morphological changes on the risk of cardiovascular disease. On the other hand, it could be hypothesised that only the most severe forms of iatrogenic Cushing's syndrome were recorded. Thirdly, no data were available on adherence to glucocorticoids. However, the frequency and dosage of glucocorticoid prescribing (duration of use, initial daily dosage, number of prescriptions during a treatment course) were similar in the two groups prescribed glucocorticoids, indicating that, on average, the level of adherence to the drug was probably quite similar between the groups. Another potential limitation is that some variables of interest could not be assessed because too few data were available during the periods of interest (for example, levels of high or low density lipoprotein cholesterol, waist to hip ratio) or because they were not routinely recorded in the database, such as exercise. Lastly, since THIN has no data on the resolution of diseases or symptoms, we were unable to ascertain whether the iatrogenic Cushing's syndrome persisted or disappeared after stopping glucocorticoids. We therefore focused merely on the first year after the index date to estimate the cardiovascular risk in people actually exhibiting morphological changes.

\section{Conclusions and policy implications}

Overall, we believe that a glucocorticoid induced cushingoid appearance should no longer be considered as a minor adverse event of glucocorticoids. It has been reported by patients as the most distressing adverse event affecting daily living and is associated with some features of the metabolic syndrome. ${ }^{36}$ Furthermore, we found that it is associated with a higher risk of cardiovascular events, particularly heart failure and coronary heart disease. It is therefore essential that patients prescribed glucocorticoids who develop iatrogenic Cushing's syndrome are assessed for cardiovascular risk and monitored regularly in both primary care and secondary care for early prevention of cardiovascular diseases.

Contributors: LF had full access to all of the data in the study and takes responsibility for the integrity of the data and the accuracy of the data analysis. LF did the statistical analyses and wrote the manuscript. IP supervised the statistical analyses and contributed to writing the manuscript. IN contributed to writing the manuscript. All authors designed the study and interpreted the data.

Funding: This study received no funding.

Competing interests: All authors have completed the ICMJE uniform disclosure form at www.icmje.org/coi_disclosure.pdf (available on request from the corresponding author) and declare no support from any organisation for the submitted work; no financial relationships with any organisations that might have an interest in the submitted work in the previous three years; no other relationships or activities that could appear to have influenced the submitted work.

Ethical approval: This study was approved by the University College London THIN steering committee and by the THIN scientific review committee.

Data sharing: No additional data available.

1 Fardet L, Petersen I, Nazareth I. Prevalence of long-term oral glucocorticoid prescriptions in the UK over the past 20 years. Rheumatology (Oxford) 2011;50:1982-90.

2 Van Staa TP, Leufkens HG, Abenhaim L, Begaud B, Zhang B, Cooper C. Use of oral corticosteroids in the United Kingdom. Q J Med 2000;93:105-11.

3 Fardet L, Flahault A, Kettaneh A, Tiev KP, Généreau T, Tolédano C, et al. Corticosteroid-induced clinical adverse events: frequency, risk factors and patient's opinion Br J Dermatol 2007;157:142-8.

4 Schou AJ, Heuck C, Wolthers OD. Differential effects of short-term prednisolone treatment on peripheral and abdominal subcutaneous thickness in children assessed by ultrasound. Steroids 2003;68:525-31.
5 Capeau J, Magré J, Caron-Debarle M, Lagathu C, Antoine B, Béréziat V, et al. Human lipodystrophies: genetic and acquired diseases of adipose tissue. Endocr Dev 2010;19:1-20.

6 Fardet L, Cabane J, Kettaneh A, Lebbé C, Flahault A. Corticosteroid-induced lipodystrophy is associated with features of the metabolic syndrome. Rheumatology (Oxford) 2007;46:1102-6.

7 Misra A, Garg A. Clinical features and metabolic derangements in acquired generalized lipodystrophy: case reports and review of the literature. Medicine (Baltimore) 2003;82:129-46.

8 Hegele RA. Premature atherosclerosis associated with monogenic insulin resistance. Circulation 2001;103:2225-9.

9 Guaraldi G, Stentarelli C, Zona S, Orlando G, Carli F, Ligabue G, et al. Lipodystrophy and anti-retroviral therapy as predictors of sub-clinical atherosclerosis in human immunodeficiency virus infected subjects. Atherosclerosis 2010;208:222-7.

10 Thiébaut R, Daucourt V, Mercié P, Ekouévi DK, Malvy D, Morlat P, et al. Lipodystrophy, metabolic disorders, and human immunodeficiency virus infection: Aquitaine Cohort, France, 1999. Clin Infect Dis 2000;31:1482-7.

11 Souverein PC, Berard A, Van Staa TP, Cooper C, Egberts AC, Leufkens HG, et al. Use of oral glucocorticoids and risk of cardiovascular and cerebrovascular disease in a population based case-control study. Heart 2004;90:859-65.

12 Wei L, MacDonald TM, Walker BR. Taking glucocorticoids by prescription is associated with subsequent cardiovascular disease. Ann Intern Med 2004;141:764-70.

13 Varas-Lorenzo C, Rodriguez LA, Maguire A, Castellsague J, Perez-Gutthann S. Use of oral corticosteroids and the risk of acute myocardial infarction. Atherosclerosis 2007;192:376-83.

14 Lis Y, Mann RD. The VAMP Research multi-purpose database in the UK. J Clin Epidemiol 1995;48:431-43.

15 Bourke A, Dattani H, Robinson M. Feasibility study and methodology to create a quality-evaluated database of primary care data. Inform Prim Care 2004;12:171-7.

16 Lewis JD, Schinnar R, Bilker WB, Wang X, Strom BL. Validation studies of the health improvement network (THIN) database for pharmacoepidemiology research. Pharmacoepidemiol Drug Saf 2007:16:393-401.

17 Ruigómez A, Martín-Merino E, Rodríguez LA. Validation of ischemic cerebrovascular diagnoses in the health improvement network (THIN). Pharmacoepidemiol Drug Saf 2010;19:579-85

18 Herrett E, Thomas SL, Schoonen WM, Smeeth L, Hall AJ. Validation and validity of diagnoses in the General Practice Research Database: a systematic review. Br J Clin Pharmacol 2010;69:4-14.

19 Lewis JD, Bilker WB, Weinstein RB, Strom BL. The relationship between time since registration and measured incidence rates in the General Practice Research Database. Pharmacoepidemiol Drug Saf 2005;14:443-51.

20 British national formulary. 2011. http://bnf.org/bnf/.

21 Chisholm J. The Read clinical classification. BMJ 1990;300:1092.

22 Davé S, Petersen I. Creating medical and drug code lists to identify cases in primary care databases. Pharmacoepidemiol Drug Saf 2009:18:704-7.

23 Capeau J, Magré J, Lascols O, Caron M, Béréziat V, Vigouroux C, et al. Diseases of adipose tissue: genetic and acquired lipodystrophies. Biochem Soc Trans 2005;33:1073-7.

24 Garg A. Acquired and inherited lipodystrophies. N Engl J Med 2004;350:1220-34.

25 Krikorian A, Khan M. Is metabolic syndrome a mild form of Cushing's syndrome? Rev Endocr Metab Disord 2010;11:141-5.

26 Bujalska IJ, Kumar S, Stewart PM. Does central obesity reflect "Cushing's disease of the omentum"? Lancet 1997;349:1210-3.

27 Fardet L, Cabane J, Lebbé C, Morel P, Flahault A. Incidence and risk factors for corticosteroid-induced lipodystrophy: a prospective study. J Am Acad Dermatol 2007;57:604-9.

28 Fardet L, Antuna-Puente B, Vatier C, Cervera P, Touati A, Simon T, et al. Adipokine profile in glucocorticoid-treated patients: baseline plasma leptin level predicts occurrence of lipodystrophy. Clin Endocrinol (Oxf) 2012 Jan 24. [Epub ahead of print.]

29 Arena C, Morin AS, Blanchon T, Hanslik T, Cabane J, Dupuy A, Fardet L. Impact of glucocorticoid-induced adverse events on adherence in patients receiving long-term systemic glucocorticoid therapy. Br J Dermatol 2010;163:832-7.

30 Strohmayer EA, Krakoff LR. Glucocorticoids and cardiovascular risk factors. Endocrinol Metab Clin North Am 2011;40:409-17.

31 Horber FF, Zürcher RM, Herren H, Crivelli MA, Robotti G, Frey FJ. Altered body fat distribution in patients with glucocorticoid treatment and in patients on long-term dialysis. Am J Clin Nutr 1986;43:758-69.

32 Lupsa BC, Sachdev V, Lungu AO, Rosing DR, Gorden P. Cardiomyopathy in congenital and acquired generalized lipodystrophy: a clinical assessment. Medicine (Baltimore) 2010;89:245-50.

33 Utz W, Engeli S, Haufe S, Kast P, Hermsdorf M, Wiesner S, et al. Myocardial steatosis, cardiac remodelling and fitness in insulin-sensitive and insulin-resistant obese women. Heart 2011;97:1585-9.

34 Szczepaniak LS, Victor RG, Orci L, Unger RH. Forgotten but not gone: the rediscovery of fatty heart, the most common unrecognized disease in America. Circ Res 2007;101:759-67.

35 McGavock JM, Lingvay I, Zib I, Tillery T, Salas N, Unger R, et al. Cardiac steatosis in diabetes mellitus: a $1 \mathrm{H}$-magnetic resonance spectroscopy study. Circulation 2007;116:1170-5.

36 Trementino L, Arnaldi G, Appolloni G, Daidone V, Scaroni C, Casonato A, et al. Coagulopathy in Cushing's syndrome. Neuroendocrinology 2010;92(Suppl 1):55-9.

37 Torén K, Lindholm NB. Do patients with severe asthma run an increased risk from ischaemic heart disease? Int J Epidemiol 1996:25:617-20.

38 Donaldson GC, Hurst JR, Smith CJ, Hubbard RB, Wedzicha JA. Increased risk of myocardial infarction and stroke following exacerbation of COPD. Chest 2010;137:1091-7.

39 Wolfe F, Mitchell DM, Sibley JT, Fries JF, Bloch DA, Williams CA, et al. The mortality of rheumatoid arthritis. Arthritis Rheum 1994;37:481-94.

40 Uddhammar A, Eriksson AL, Nyström L, Stenling R, Rantapää-Dahlqvist S. Increased mortality due to cardiovascular disease in patients with giant cell arteritis in northern Sweden. J Rheumatol 2002;29:737-42.

Accepted: 6 July 2012 


\section{What is already known on this topic}

About $1 \%$ of the general population use systemic glucocorticoids long term Glucocorticoids are associated with an increased risk of cardiovascular events

Many people taking glucocorticoids develop iatrogenic Cushing's syndrome and such people are at higher risk of metabolic disorders

\section{What this study adds}

The risk of cardiovascular events in people treated with glucocorticoids is nearly three times greater in those who develop iatrogenic Cushing's syndrome

This raises the question of whether glucocorticoids increase the risk of cardiovascular events in all users or only in those with iatrogenic Cushing's syndrome

People treated with glucocorticoids who develop iatrogenic Cushing's syndrome should be aggressively targeted for early screening and management of cardiovascular risk factors

This is an open-access article distributed under the terms of the Creative Commons Attribution Non-commercial License, which permits use, distribution, and reproduction in any medium, provided the original work is properly cited, the use is non commercial and is otherwise in compliance with the license. See: http://creativecommons.org/licenses/bync/2.0/ and http://creativecommons.org/licenses/by-nc/2.0/legalcode. 


\section{Tables}

\begin{tabular}{|c|c|c|c|}
\hline \multirow[b]{2}{*}{ Characteristics } & \multicolumn{2}{|c|}{ Glucocorticoids } & \multirow[b]{2}{*}{$\begin{array}{l}\text { No glucocorticoids } \\
\qquad(n=3282)\end{array}$} \\
\hline & $\begin{array}{l}\text { latrogenic Cushing's syndrome } \\
\qquad(n=547)\end{array}$ & $\begin{array}{l}\text { No iatrogenic Cushing's syndrome } \\
\qquad(n=3231)\end{array}$ & \\
\hline Women & $391(71.5)$ & $2301(71.2)$ & $2346(71.5)$ \\
\hline Median (interquartile range) age at index date (years) & $64.7(51.1-74.4)$ & $64.3(51.0-74.4)$ & $63.7(50.9-74.4)$ \\
\hline \multicolumn{4}{|l|}{ No of previous treatments with glucocorticoids: } \\
\hline 0 & $276(50.5)$ & $1057(32.7)$ & $3282(100)$ \\
\hline 1 & $114(20.8)$ & $556(17.2)$ & - \\
\hline 2 & $57(10.4)$ & $368(11.4)$ & - \\
\hline 3 & $28(5.1)$ & $274(8.5)$ & - \\
\hline$\geq 4$ & $72(13.2)$ & $976(30.2)$ & - \\
\hline $\begin{array}{l}\text { Median (interquartile range) initial prednisone equivalent } \\
\text { dosage (mg/day) }\end{array}$ & $28(7.5-45)$ & $25(5-40)$ & - \\
\hline $\begin{array}{l}\text { Median (interquartile range) duration of glucocorticoid } \\
\text { use before index date (months) }\end{array}$ & $3.4(1.3-9.1)$ & $4.1(2.1-9.5)$ & - \\
\hline $\begin{array}{l}\text { Median (interquartile range) cumulative dose of } \\
\text { prednisone equivalent before index date (mg/day) }\end{array}$ & $2295(875-3220)$ & $2485(835-3290)$ & - \\
\hline $\begin{array}{l}\text { Median (interquartile range) total duration of glucocorticoid } \\
\text { treatment (months) }\end{array}$ & $8.4(2.5-25.5)$ & $9.6(4.2-23.2)$ & - \\
\hline $\begin{array}{l}\text { Median (interquartile range) No of recorded glucocorticoid } \\
\text { prescriptions during treatment }\end{array}$ & $6(4-14)$ & $7(4-13)$ & \\
\hline \multicolumn{4}{|l|}{ Smoking status: } \\
\hline Never smoker & $356(65.1)$ & $1984(61.4)$ & $2284(69.6)$ \\
\hline Former smoker & $33(6.0)$ & $186(5.8)$ & $158(4.8)$ \\
\hline Current smoker & $158(28.9)$ & $1061(32.8)$ & $840(25.6)$ \\
\hline \multicolumn{4}{|l|}{ Diseases treated with glucocorticoids: } \\
\hline Asthma & $94(17.2)$ & $918(28.4)$ & $551(16.8)$ \\
\hline Chronic obstructive pulmonary disease & $41(7.5)$ & $453(14.0)$ & $270(8.2)$ \\
\hline Rheumatoid arthritis & $40(7.3)$ & $192(6.0)$ & $88(2.7)$ \\
\hline Polymyalgia rheumatica or giant cell arteritis & $121(22.1)$ & $404(12.5)$ & $8(0.3)$ \\
\hline Crohn's disease & $15(2.7)$ & $53(1.6)$ & $16(0.5)$ \\
\hline Ulcerative colitis & $18(3.3)$ & $56(1.7)$ & $24(0.7)$ \\
\hline Other & $92(16.8)$ & $527(16.3)$ & $1605(48.9)$ \\
\hline Missing & $126(23.1)$ & $628(19.5)$ & $720(21.9)$ \\
\hline \multicolumn{4}{|l|}{ Previously prescribed drugs: } \\
\hline Diuretics & $154(28.1)$ & $752(23.3)$ & $508(15.5)$ \\
\hline$\beta$ blockers & $63(11.5)$ & $307(9.5)$ & $322(9.8)$ \\
\hline a blockers & $15(2.7)$ & $83(2.6)$ & $64(2.0)$ \\
\hline Calcium channel blockers & $77(14.0)$ & $405(12.6)$ & $285(8.7)$ \\
\hline Nitrates & $45(8.2)$ & $171(5.3)$ & $113(3.5)$ \\
\hline Angiotensin converting enzyme inhibitors & $85(15.5)$ & $504(15.6)$ & $362(11.0)$ \\
\hline Oral anticoagulants & $19(3.4)$ & $104(3.2)$ & $69(2.1)$ \\
\hline Aspirin & $84(15.3)$ & $455(14.1)$ & $363(11.1)$ \\
\hline Lipid lowering drugs & $65(11.9)$ & $409(12.6)$ & $379(11.6)$ \\
\hline Diabetes drugs & $23(4.2)$ & $152(4.7)$ & $123(3.8)$ \\
\hline
\end{tabular}




\begin{tabular}{|c|c|c|c|c|c|c|c|}
\hline \multirow[b]{3}{*}{$\begin{array}{l}\text { Variables in relation to } \\
\text { index date }\end{array}$} & \multicolumn{4}{|c|}{ Glucocorticoids } & \multirow{2}{*}{\multicolumn{2}{|c|}{ No glucocorticoids $(n=3282)$}} & \multirow[b]{3}{*}{ P values } \\
\hline & \multicolumn{2}{|c|}{$\begin{array}{l}\text { latrogenic Cushing's syndrome } \\
\qquad(n=547)\end{array}$} & \multicolumn{2}{|c|}{$\begin{array}{l}\text { No iatrogenic Cushing's syndrome } \\
\qquad(\mathrm{n}=3231)\end{array}$} & & & \\
\hline & No & $\begin{array}{l}\text { Median (interquartile } \\
\text { range) }\end{array}$ & No & $\begin{array}{l}\text { Median (interquartile } \\
\text { range) }\end{array}$ & No & $\begin{array}{l}\text { Median (interquartile } \\
\text { range) }\end{array}$ & \\
\hline \multicolumn{8}{|l|}{ Body mass index $\left(\mathrm{kg} / \mathrm{m}^{2}\right)$ : } \\
\hline 6 months before & 187 & $26.2(23.2-31.8)$ & 1172 & $26.4(23.0-30.2)$ & 1071 & $26.0(22.9-29.9)$ & 0.33 \\
\hline 6 months after & 150 & $28.5(24.8-33.0)$ & 896 & $27.1(23.8-31.6)$ & 758 & $26.9(23.4-30.8)$ & 0.003 \\
\hline \multicolumn{8}{|c|}{$\begin{array}{l}\text { Systolic blood pressure }(\mathrm{mm} \\
\mathrm{Hg} \text { ): }\end{array}$} \\
\hline 6 months before & 352 & $130(118-145)$ & 2092 & $130(120-140)$ & 1849 & $130(120-140)$ & 0.35 \\
\hline 6 months after & 304 & $150(131-165)$ & 1912 & $141(130-160)$ & 1462 & $140(130-158)$ & $<0.001$ \\
\hline \multicolumn{8}{|c|}{$\begin{array}{l}\text { Diastolic blood pressure }(\mathrm{mm} \\
\mathrm{Hg}) \text { : }\end{array}$} \\
\hline 6 months before & 352 & $75(70-80)$ & 2092 & $76(70-80)$ & 1849 & $76(70-80)$ & 0.55 \\
\hline 6 months after & 304 & $86(80-95)$ & 1912 & $80(76-90)$ & 1462 & $80(75-90)$ & $<0.001$ \\
\hline \multicolumn{8}{|l|}{ Fasting glucose (mmol/L): } \\
\hline 6 months before & 156 & $5.1(4.4-5.9)$ & 895 & $5.0(4.6-5.8)$ & 736 & $5.2(4.7-5.9)$ & 0.16 \\
\hline 6 months after & 156 & $6.0(5.0-7.8)$ & 830 & $5.4(4.8-6.6)$ & 588 & $5.4(4.8-6.5)$ & 0.002 \\
\hline \multicolumn{8}{|l|}{$\begin{array}{l}\text { Fasting total cholesterol } \\
(\mathrm{mmol} / \mathrm{L}) \text { : }\end{array}$} \\
\hline 6 months before & 118 & $5.0(4.4-6.3)$ & 817 & $4.9(4.2-5.8)$ & 785 & $4.9(4.0-5.7)$ & 0.08 \\
\hline 6 months after & 120 & $5.8(5.0-7.8)$ & 767 & $5.2(4.4-6.1)$ & 678 & $5.1(4.4-6.0)$ & $<0.001$ \\
\hline \multicolumn{8}{|c|}{ Fasting triglycerides (mmol/L): } \\
\hline 6 months before & 77 & $1.4(1.0-1.8)$ & 570 & $1.4(1.0-1.9)$ & 620 & $1.3(1.0-1.9)$ & 0.31 \\
\hline 6 months after & 79 & $1.9(1.3-2.7)$ & 547 & $1.4(1.0-2.1)$ & 492 & $1.4(1.1-2.0)$ & $<0.001$ \\
\hline
\end{tabular}


Table 3| Initiation of treatments within year after index date (up to date of cardiovascular event). Values are numbers (percentages) of participants unless stated otherwise

Glucocorticoids

Treatments latrogenic Cushing's syndrome $(n=547)$ No iatrogenic Cushing's syndrome $(n=3231) \quad$ No glucocorticoids $(n=3282) \quad P$ values

\begin{tabular}{lcccc} 
Antihypertensive drugs & $81(14.8)$ & $295(9.1)$ & $<0.001$ & $211(6.4)$ \\
\hline Lipid lowering drugs & $20(3.7)$ & $76(2.3)$ & $79(2.4)$ & 0.18 \\
\hline Diabetes drugs & $14(2.6)$ & $19(0.6)$ & $<(0.3)$ & $<0.001$
\end{tabular}

Diabetes drugs 
Table 4| Recorded codes for cardiovascular events within year after index date

\section{Codes}

No $(\%)$ of patients $(n=341)$

Coronary heart disease: 177 (52)

\begin{tabular}{|c|c|}
\hline Angina pectoris & 71 \\
\hline Ischaemic heart disease & 41 \\
\hline Acute myocardial infarction & 30 \\
\hline Unstable angina & 7 \\
\hline Acute non-ST segment elevated myocardial infarction & 5 \\
\hline Coronary artery disease & 3 \\
\hline Transluminal balloon angioplasty of coronary artery & 8 \\
\hline Angioplasty of coronary artery & 6 \\
\hline Acute coronary syndrome & 2 \\
\hline Acute inferolateral infarction & 1 \\
\hline Acute subendocardial infarction & 1 \\
\hline Anterior myocardial infarction & 1 \\
\hline Heart attack & 1 \\
\hline Heart failure: & $101(30)$ \\
\hline Congestive cardiac failure & 28 \\
\hline Congestive heart failure & 25 \\
\hline Left ventricular failure & 24 \\
\hline Heart failure & 18 \\
\hline Cardiac failure & 3 \\
\hline Cardiac insufficiency & 1 \\
\hline Decompensated cardiac failure & 1 \\
\hline Heart failure confirmed & 1 \\
\hline Cerebrovascular events: & $63(18)$ \\
\hline Stroke and cerebrovascular accident & 22 \\
\hline Transient ischaemic attack & 14 \\
\hline Transient cerebral ischaemia & 12 \\
\hline Cerebrovascular accident unspecified & 8 \\
\hline Cerebral artery occlusion & 4 \\
\hline Cerebral infarction & 2 \\
\hline Left sided cerebral infarction & 1 \\
\hline
\end{tabular}


Table 5| Adjusted hazard ratios (95\% confidence intervals) of cardiovascular events in patients with iatrogenic Cushing's syndrome

\begin{tabular}{|c|c|c|c|c|c|c|c|c|}
\hline \multirow[b]{2}{*}{$\begin{array}{l}\text { Cardiovascular } \\
\text { events }\end{array}$} & \multicolumn{4}{|c|}{$\begin{array}{l}\text { Compared with patients without iatrogenic Cushing's syndrome } \\
\qquad(n=3231)\end{array}$} & \multicolumn{4}{|c|}{$\begin{array}{l}\text { Compared with patients not prescribed glucocorticoids } \\
\qquad(n=3282)\end{array}$} \\
\hline & $\begin{array}{l}\text { Crude hazard } \\
\text { ratio }(95 \% \mathrm{Cl})\end{array}$ & $P$ value & $\begin{array}{l}\text { Adjusted hazard } \\
\text { ratio* }(95 \% \mathrm{Cl})\end{array}$ & $P$ value & $\begin{array}{l}\text { Crude hazard } \\
\text { ratio }(95 \% \mathrm{Cl})\end{array}$ & $P$ value & $\begin{array}{l}\text { Adjusted hazard } \\
\text { ratiot }(95 \% \mathrm{Cl})\end{array}$ & $P$ value \\
\hline All $(n=341)$ & 2.33 (1.73 to 3.14$)$ & $<0.001$ & 2.74 (2.06 to 3.62 ) & $<0.001$ & 3.70 (2.63 to 5.22 ) & $<0.001$ & 4.16 (2.98 to 5.82 ) & $<0.001$ \\
\hline $\begin{array}{l}\text { Coronary heart } \\
\text { disease }(n=177)\end{array}$ & 1.96 (1.29 to 2.97$)$ & 0.002 & 2.27 (1.48 to 3.47 ) & $<0.001$ & 2.97 (1.91 to 4.64$)$ & $<0.001$ & 2.68 (1.62 to 4.44$)$ & $<0.001$ \\
\hline $\begin{array}{l}\text { Cerebrovascular } \\
\text { event }(n=63)\end{array}$ & 2.26 (1.06 to 4.81$)$ & 0.02 & 2.23 (0.96 to 5.17$)$ & 0.07 & 1.79 (0.85 to 3.76$)$ & 0.12 & 2.14 (0.97 to 4.73$)$ & 0.06 \\
\hline $\begin{array}{l}\text { Heart failure } \\
(\mathrm{n}=101)\end{array}$ & 2.97 (1.82 to 4.84$)$ & $<0.001$ & 3.77 (2.41 to 5.90$)$ & $<0.001$ & $\begin{array}{l}9.74(4.98 \text { to } \\
19.06)\end{array}$ & $<0.001$ & $\begin{array}{l}13.31(7.24 \text { to } \\
24.51)\end{array}$ & $<0.001$ \\
\hline
\end{tabular}

*Adjusted for age, sex, initial dosage of glucocorticoids and duration of use, underlying disease, smoking status, and use of aspirin, oral anticoagulants, diabetes drugs, antihypertensive drugs, and cholesterol lowering drugs.

†Adjusted for age, sex, underlying disease, smoking status, and use of aspirin, oral anticoagulants, diabetes drugs, antihypertensive drugs, and cholesterol lowering drugs. 
Table 6 | Risk of negative control diseases in patients with iatrogenic Cushing's syndrome

\begin{tabular}{|c|c|c|c|c|c|c|c|c|}
\hline \multirow[b]{2}{*}{$\begin{array}{l}\text { Negative } \\
\text { diseases }\end{array}$} & \multicolumn{4}{|c|}{$\begin{array}{l}\text { Compared with patients without iatrogenic Cushing's syndrome } \\
\qquad(\mathrm{n}=3231)\end{array}$} & \multicolumn{4}{|c|}{ Compared with patients not prescribed glucocorticoids $(n=3282)$} \\
\hline & $\begin{array}{l}\text { Crude hazard ratio } \\
\qquad(95 \% \mathrm{Cl})\end{array}$ & $P$ value & $\begin{array}{l}\text { Adjusted hazard } \\
\text { ratio* }^{*}(95 \% \mathrm{Cl})\end{array}$ & $P$ value & $\begin{array}{l}\text { Crude hazard ratio } \\
\qquad(95 \% \mathrm{Cl})\end{array}$ & $P$ value & $\begin{array}{l}\text { Adjusted hazard } \\
\text { ratio† }(95 \% \mathrm{Cl})\end{array}$ & $P$ value \\
\hline $\begin{array}{l}\text { Valvular heart } \\
\text { disease }(n=41)\end{array}$ & 1.39 (0.47 to 4.07$)$ & 0.55 & 1.23 (0.44 to 3.43$)$ & 0.69 & 2.55 (0.79 to 8.24$)$ & 0.11 & 0.89 (0.26 to 3.08$)$ & 0.85 \\
\hline Sprain $(n=88)$ & 0.67 (0.22 to 2.02$)$ & 0.48 & $0.74(0.23$ to 0.37$)$ & 0.61 & $1.32(0.41$ to 4.26$)$ & 0.63 & $1.58(0.37$ to 6.76$)$ & 0.54 \\
\hline $\begin{array}{l}\text { Neoplasm } \\
(\mathrm{n}=78)\end{array}$ & $1.59(0.81$ to 3.14$)$ & 0.18 & 1.85 (0.92 to 3.71$)$ & 0.08 & 1.99 (1.01 to 3.97$)$ & 0.04 & $3.68(1.83$ to 7.44$)$ & $<0.001$ \\
\hline $\begin{array}{l}\text { Impacted } \\
\text { cerumen in ear } \\
(\mathrm{n}=288)\end{array}$ & 0.89 (0.58 to 1.37$)$ & 0.59 & 0.94 (0.61 to 1.45$)$ & 0.78 & 1.01 (0.63 to 1.63$)$ & 0.95 & 1.02 (0.56 to 1.87$)$ & 0.94 \\
\hline
\end{tabular}

*Adjusted for age, sex, initial dosage of glucocorticoid and duration of use, and underlying disease.

†Adjusted for age, sex, and underlying disease. 


\section{Figure}

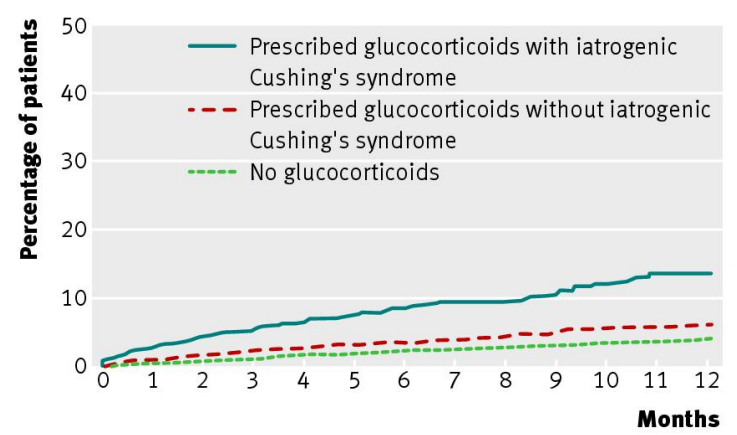

Kaplan-Meier survival curves showing cumulative incidence of cardiovascular events over time in the three study groups 